http://jurnaltarbiyah.uinsu.ac.id/index.php/raudhah

e-mail: jurnalraudhah@uinsu.ac.id

p-ISSN: 2338-2163

e-ISSN: $2716-2435$

\title{
Pengaruh Model Pembelajaran Make A Match Terhadap Perkembangan Sosial Anak Usia 5-6 di TK Anugrah Medan
}

\author{
${ }^{1}$ Khotimatul Majidah S \\ STAIS Medan \\ Email:khotimatulmajidah28@gmail.com
}

${ }^{2}$ Fatmah Syarah

UIN Sumatera Utara Medan

email: Fasyarah@gmail.com

Article received : 20 Agustus 2021

Article accepted : 11 Oktober 2021
Review process : 20 September 2021

Article published : 01 Desember 2021

\begin{abstract}
Abstrak
Penelitian ini bertujuan untuk mengetahui Perkembangan dan pengaruh sosial anak usia 5-6 tahun dalam penggunaan model pembelajaran make a match. Penelitian yang digunakan yaitu kuantitatif (Quasi Eksperimen Design), menggunakan 2 kelas yaitu eksperimen dan kontrol. Jumlah populasi adalah 38 anak. Pengambilan sampel penelitian ini menggunakan total sampling yaitu mengambil seluruh populasi menjadi sampel. Instrumen penelitian ini menggunakan lembar observasi, teknik analisis data, menggunakan uji normalitas, homogenitas dan hipotesis. Hasil penelitian ini yaitu Pertama Perkembangan sosial anak usia 5-6 tahun di TK Anugrah dibuktikan melalui observasi sebelum menggunakan model pembelajaran make a match pada kelas eksperimen diperoleh dengan nilai rata-rata 7,26 dengan nilai terendah 5, dan nilai tertinggi 9, modusnya 8 , dan mediannya 8 . Kemudian menggunakan model kelompok diperoleh dengan nilai rata-rata 8,11 dengan nilai terendah 5 dan nilai tertinggi 12 , modusnya 8 , mediannya 8 , dan simpangan baku $1,761.2$ ) Penggunaan model pembelajaran make a match terhadap perkembangan sosial anak usia 5-6 tahun diperoleh dengan nilai rata-rata 17,53 dengan nilai terendah 15 dan nilai tertinggi 20, modusnya 18 dan mediannya 18. Jadi, perkembangan sosial anak usia 5-6 tahun di TK Anugrah menggunakan model pembelajaran make a match sudah berkembang secara optimal, Kedua Terdapat pengaruh model pembelajaran Make A Match terhadap perkembangan sosial anak usia sebesar 0,05 didapat $\mathrm{t}_{\text {tabel }}$ pada $\alpha$ diperoleh nilai $\mathrm{t}_{\text {hitung }}=24.8969$ dengan taraf dt 17 diperoleh nilai $t_{\text {tabel }}=2,10982$. Karena $t_{\text {hitung }}>t_{\text {tabel }}$ maka $H 0:$ ditolak, $\mathrm{H}_{\mathrm{a}}:$ diterima
\end{abstract}

Kata kunci: Perkembangan sosial; Make A Match; Paud

\begin{abstract}
This study aims to determine the development and social influence of children aged 5-6 years in the use of the make a match learning model. The research used is quantitative (Quasi Experimental Design), using 2 classes, namely experimental and control. The total population is 38 children. Sampling in this study used total sampling, namely taking the entire population as a sample. This research instrument uses observation sheets, data analysis techniques, using normality, homogeneity and hypothesis tests. The results of this study are: First, the social development of children aged 5-6 years in Anugrah Kindergarten is proven through observation before using the make a match learning model in the experimental class obtained with an average value of 7.26 with the lowest score of 5, and the highest score of 9, the mode is 8 , and the median is 8 . Then using the group model, the average value is 8.11 with the lowest value 5 and the highest value being 12, the mode is 8 , the median is 8 , and the standard deviation is 1.761. 2) The use of the make a match learning model on the social development of children aged 5-6 years is obtained with an average value of 17.53 with the lowest score of 15 and the highest score of 20, the mode is 18 and the median is 18. So, the social development of
\end{abstract}


http://jurnaltarbiyah.uinsu.ac.id/index.php/raudhah

e-mail: jurnalraudhah@uinsu.ac.id

p-ISSN: 2338-2163

e-ISSN: $2716-2435$

children aged 5-6 years in Kindergarten Anugrah using the make a match learning model has developed optimally, Second There is the effect of the Make A Match learning model on the social development of children aged 0.05, obtained ttable in, the value of tcount $=24.8969$ with dt level of 17 obtained the value of ttable = 2 ,10982. Because tcount $>t$ table then HO : rejected, Ha : accepted

Keywords: Social development; Make A Match; Paud

\section{A. PENDAhULUAN}

Sosial anak mengalami perkembangan yang pesat, maka orang tua di rumah dan guru di sekolah berpengaruh kepada anak. Semua ini dasar utama pengembangan sosial dalam mencetak jati diri anak dengan nilai yang ada di lingkungan. Perilaku tersebut wajib dilakukan dalam kesehariannya, meliputi perilaku yang baik, jujur, disiplin, kemandirian, tanggung jawab, percaya diri, adil, kasih sayang terhadap sesama.

Munculnya perilaku itu karena adanya dorongan, keinginan yang kuat dari seseorang. Faktor yang mempengaruhi perkembangan sosial menurut Femmi Nurmalitasari, hubungan anak dengan orang tua, anggota keluarga, lingkungan sekolah, dan lingkungan masyarakat.(Femmi, Nurmalitasari,, 2015) Tidak sadar anak berbaur dan berinteraksi kepada sekitarnya. Perkembangan sosial didapat dari respon yang sehat dan kesempatan yang diberikan kepada anak. Dalam aktivitas bermain, anak mengembangkan sikap terhadap temannya.

Guru harus mengerti pertumbuhan dan perkembangannya, guna membantu anak lebih cepat menstimulus perkembangan pada dirinya, sehingga guru mempersiapkan konsep pembelajaran dengan model pembelajaran yang menarik sesuai kebutuhannya untuk cepat merangsang pertumbuhan dan perkembangan khususnya pada perkembangan sosial anak. Jika guru tidak dapat mengelola kelas dengan menggunakan model pembelajaran vakum dan tidak membuat anak belajar dengan aktif dan kreatif. Maka setiap perkembangan pada anak tidak berkembangan dengan baik.

Model pembelajaran untuk sosial pada anak salah satunya model pembelajaran make a match. Make a match memiliki tujuan yang tinggi untuk membantu perkembangan anak, mengembangkan kognitif, sosial secara bersamaan. Keduanya penting untuk perkembangan diri anak. Penelitian Rahyuni pembelajaran Make a match mengutamakan penanaman kerja sama serta kemampuan berinteraksidengan media kartu bergambar. Model pembelajaran Make a Match adalah salah satu model pembelajaran kooperatif yang mudah diterapkan karena anak akan mencari pasangan sambil belajar mengenai suatu konsep atau topik dalam suasana yang menyenangkan, sesuai dengan prinsip pendidikan bahwa anak usia dini belajar melalui bermain (Rahyuni,2014)

Peneliti akan melakukan perlakuan dengan menggunakan model pembelajaran Make a Match yang jarang diaplikasikan guru di dalam kelas maupun di luar, agar terlihat sosial anak, menjadikan anak memiliki imajinasi dan kekreatifan yang baru di dalam dan di luar kelas. 
http://jurnaltarbiyah.uinsu.ac.id/index.php/raudhah

e-mail: jurnalraudhah@uinsu.ac.id

p-ISSN: 2338-2163

e-ISSN: 2716-2435

Menjadikan anak tidak bosan dan jenuh ketika mengikuti pembelajaran yang berlangsung. Model pembelajaran make a match ini diinginkan untuk meningkatkan sosial anak serta membawa perubahan pembelajaran yang menarik bagi anak, dimana model pembelajaran make a match memancing anak untuk lebih kreatif, mandiri serta berkarya dan ada peningkatan pada hasil sebelumnya.

\section{B. METODE PENELITIAN}

Penelitian ini menggunakan Quasi Experimental Design. Quasi Experimental .(Maisarah, 2019). Pada penelitian Quasi Experimental menggunakan tipe Non-equivalent Control Group Design. Populasi pada penelitian ini adalah seluruh anak kelompok B (Usia 5-6 tahun) sebanyak 38 orang anak yang terdiri dari 2 kelas yaitu kelas B1 terdiri dari 19 anak, dengan jumlah laki-laki sebanyak 9 orang dan perempuan 10 orang serta kelas B2 terdiri dari 19 anak, dengan jumlah anak laki-laki 9 orang dan perempuan 10 orang. Peneliti menggunakan teknik pengumpulan data dengan menggunakan Observasi. Hasil data di analisis secara deskriptif kemudian disajikan dalam bentuk daftar distribusi frekuensi beserta grafiknya. Selanjutnya melakukan perhitungan untuk menguji hipotesis dengan teknik analisis data yang digunakan adalah statistik inferensial. Untuk menguji hipotesis yang telah diajukan dengan Uji-t.

\section{HASIL TEMUAN DAN PEMBAHASAN}

\section{Deskripsi Data Hasil Penelitian}

Data dalam penelitian ini dikumpulkan dengan menggunakan teknik observasi. Lembar observasi yang telah disusun digunakan untuk mengamati data perkembangan sosial anak. Pada saat kegiatan berlangsung di observasi dengan menggunakan instrumen yang telah disiapkan. Untuk mengetahui gambaran tentang karakteristik data dan hasil observasi yang dilakukan pada kegiatan tersebut. Kelas eksperimen berjumlah 19 anak dan kelas kontrol berjumlah 19 anak. Penelitian menggunakan model pembelajaran make a match pada kelas eksperimen. Sebelum diadakan penelitian terlebih dahulu dilakukan pre test atau tes awal. Tujuannya untuk mengetahui perkembangan sosial anak menggunakan model pembelajaran make a match.

a. Hasil observasi perkembangan sosial anak menggunakan model pembelajaran bank make a match di TK Anugrah Medan 
http://jurnaltarbiyah.uinsu.ac.id/index.php/raudhah e-mail: jurnalraudhah@uinsu.ac.id

Tabel 1. Hasil observasi perkembangan sosial anak usia 5-6 tahun dengan menggunakan model pembelajaran make a match pada kelas eksperimen

\begin{tabular}{|c|c|c|}
\hline No & $\begin{array}{c}\text { Kelas Eksperimen } \\
\text { Pre Test }\left(\mathrm{Y}_{1}\right)\end{array}$ & $\begin{array}{l}\text { Kelas Eksperimen } \\
\text { Post Test }\left(\mathrm{X}_{1}\right)\end{array}$ \\
\hline E1 & 5 & 15 \\
\hline E2 & 5 & 15 \\
\hline E3 & 5 & 15 \\
\hline E4 & 5 & 16 \\
\hline E5 & 6 & 16 \\
\hline E6 & 6 & 16 \\
\hline E7 & 7 & 17 \\
\hline E8 & 7 & 17 \\
\hline E9 & 7 & 17 \\
\hline E10 & 8 & 18 \\
\hline E11 & 8 & 18 \\
\hline E12 & 8 & 18 \\
\hline E13 & 8 & 18 \\
\hline E14 & 8 & 20 \\
\hline E15 & 9 & 20 \\
\hline E16 & 9 & 19 \\
\hline E17 & 9 & 19 \\
\hline E18 & 9 & 19 \\
\hline E19 & 9 & 20 \\
\hline Jumlah & 138 & 333 \\
\hline $\begin{array}{l}\text { Rata- } \\
\text { rata }\end{array}$ & 7.26 & 17.53 \\
\hline Modus & 8 & 18 \\
\hline Median & 8 & 18 \\
\hline
\end{tabular}

Dari tabel di atas, diketahui bahwa hasil observasi perkembangan sosial anak usia 5-6 tahun sebelum menggunakan model pembelajaran make a match pre test di kelas eksperimen dengan memperoleh nilai rata-rata 7.26 dengan nilai terendah 5 dan nilai tertinggi 9 , modusnya 8 , dan mediannya 8 . Kemudian hasil observasi dengan menggunakan model pembelajaran make a match serta post test di kelas eksperimen dengan memperoleh ratarata 17.53 dengan nilai terendah 15 dan nilai tertinggi 20 , modusnya 18 dan mediannya 18. 
http://jurnaltarbiyah.uinsu.ac.id/index.php/raudhah e-mail: jurnalraudhah@uinsu.ac.id

p-ISSN: 2338-2163

Tabel 2. Hasil observasi perkembangan sosial anak usia 5-6 tahun dengan menggunakan model pembelajaran kelompok pada kelas kontrol

\begin{tabular}{|c|c|c|}
\hline No & $\begin{array}{c}\text { Kelas Kontrol } \\
\text { Pre Test }\left(\mathrm{Y}_{1}\right)\end{array}$ & $\begin{array}{l}\text { Kelas Kontrol } \\
\text { Post Test }\left(\mathrm{X}_{1}\right)\end{array}$ \\
\hline K1 & 5 & 6 \\
\hline K2 & 5 & 5 \\
\hline K3 & 5 & 6 \\
\hline K4 & 5 & 6 \\
\hline K5 & 5 & 7 \\
\hline K6 & 6 & 7 \\
\hline K7 & 6 & 7 \\
\hline K8 & 7 & 8 \\
\hline K9 & 7 & 8 \\
\hline K10 & 7 & 9 \\
\hline K11 & 7 & 8 \\
\hline K12 & 7 & 8 \\
\hline K13 & 8 & 9 \\
\hline K14 & 8 & 9 \\
\hline K15 & 8 & 10 \\
\hline K16 & 9 & 9 \\
\hline K17 & 9 & 10 \\
\hline K18 & 9 & 10 \\
\hline K19 & 9 & 12 \\
\hline Jumlah & 132 & 154 \\
\hline Rata-rata & 6.95 & 8.11 \\
\hline Modus & 5 & 8 \\
\hline Median & 7 & 8 \\
\hline
\end{tabular}

Dari tabel di atas, diketahui bahwa hasil observasi perkembangan sosial anak usia 5-6 tahun sebelum menggunakan model pembelajaran kelompok pada kelas kontrol pre test diperoleh dengan nilai rata-rata 6.95 dengan nilai terendah 5 dan nilai tertinggi 9, modusnya 5 dan mediannya 7. Kemudian post test pada kelas kontrol dengan menggunakan model pembelajaran kelompok diperoleh dengan nilai rata-rata 8.11 dengan nilai terendah 5 dan nilai tertinggi 12 , modusnya 8 dan mediannya 8 .

b. Nilai Pre Test Perkembangan Sosial Anak Usia 5-6 Tahun Kelas Eksperimen Dan Kelas Kontrol

Dari hasil pre test di atas, diperoleh nilai rata-rata perkembangan sosial anak usia 5-6 tahun pada kelas eksperimen adalah 7.53, sedangkan nilai rata-rata perkembangan sosial anak pada kelas kontrol adalah 6.95. Ternyata dari 
http://jurnaltarbiyah.uinsu.ac.id/index.php/raudhah e-mail: jurnalraudhah@uinsu.ac.id

pengujian nilai pre test kelas eksperimen dan kelas kontrol dengan kelas yang berbeda memiliki perkembangan awal yang sama (normal). Berikut adalah ringkasan hasil pre test kelas eksperimen dan kelas kontrol pada tabel berikut:

Tabel 3. Hasil Pre Test Kelas Eksperimen dan Kelas Kontrol

\begin{tabular}{|c|l|c|c|}
\hline No & Statistika & $\begin{array}{c}\text { Kelas } \\
\text { Eksperimen }\end{array}$ & $\begin{array}{c}\text { Kelas } \\
\text { Kontrol }\end{array}$ \\
\hline $\mathbf{1}$ & N & 19 & 19 \\
\hline $\mathbf{2}$ & Jumlah Skor & 138 & 132 \\
\hline $\mathbf{3}$ & Rata-rata & 7.26 & 6.95 \\
\hline $\mathbf{4}$ & S.Baku & 1.522 & 1.508 \\
\hline $\mathbf{5}$ & Varians & 2.19 & 2.16 \\
\hline $\mathbf{6}$ & Maksimum & 9 & 9 \\
\hline $\mathbf{7}$ & Minimum & 5 & 5 \\
\hline
\end{tabular}

Dari informasi yang disajikan dalam tabel di atas dapat dilihat kelas ekperimen dan kelas kontrol dalam hal perhitungan statistika pre test sebelum diberikan perlakuan yang berbeda. Berikut diagram perhitungan statistika pre test pada kelas eksperimen dan kelas kontrol.

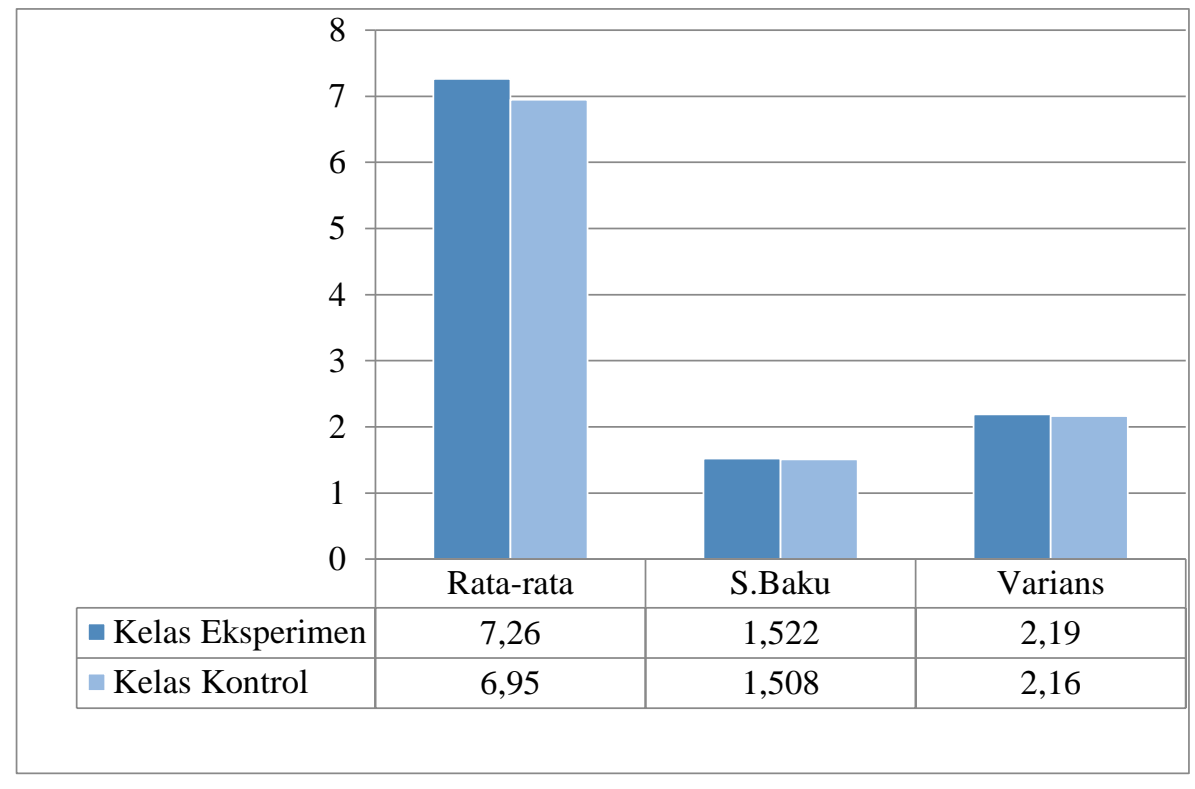

Gambar 1 Diagram Data Pre Test Kelas Eksperimen dan Kelas Kontrol 
http://jurnaltarbiyah.uinsu.ac.id/index.php/raudhah e-mail: jurnalraudhah@uinsu.ac.id

c. Nilai Post Test Perkembangan Sosial Anak Usia 5-6 Tahun Pada Kelas Eksperimen dan Kelas Kontrol

Dari hasil post test di atas, diperoleh nilai rata-rata perkembangan sosial anak usia 5-6 tahun pada kelas eksperimen adalah 17.79, sedangkan nilai ratarata perkembangan sosial anak pada kelas kontrol adalah 8.21. Ternyata dari pengujian nilai post test kelas eksperimen dan kelas kontrol telah memiliki perbedaan, karena telah diberikan perlakuan yang berbeda. Untuk kelas eksperimen diterapkan dengan model pembelajaran make a match sedangkan pada kelas kontrol diterapkan dengan model pembelajaran kelompok.

Tabel 4. Hasil Post Test Kelas Eksperimen dan Kelas Kontrol

\begin{tabular}{|c|l|c|c|}
\hline No & Statistika & $\begin{array}{c}\text { Kelas } \\
\text { Eksperimen }\end{array}$ & $\begin{array}{c}\text { Kelas } \\
\text { Kontrol }\end{array}$ \\
\hline 1 & N & 19 & 19 \\
\hline 2 & Jumlah Skor & 333 & 154 \\
\hline 3 & Rata-rata & 17.53 & 8.11 \\
\hline 4 & S.Baku & 1.712 & 1.761 \\
\hline 5 & Varians & 2.78 & 2.94 \\
\hline 6 & Maksimum & 20 & 5 \\
\hline 7 & Minimum & 15 & 12 \\
\hline
\end{tabular}

Berikut disajikan diagram perbedaan perhitungan statistika post test pada kelas ekperimen dan kelas kontrol. 
http://jurnaltarbiyah.uinsu.ac.id/index.php/raudhah e-mail: jurnalraudhah@uinsu.ac.id

p-ISSN: 2338-2163

e-ISSN: $2716-2435$

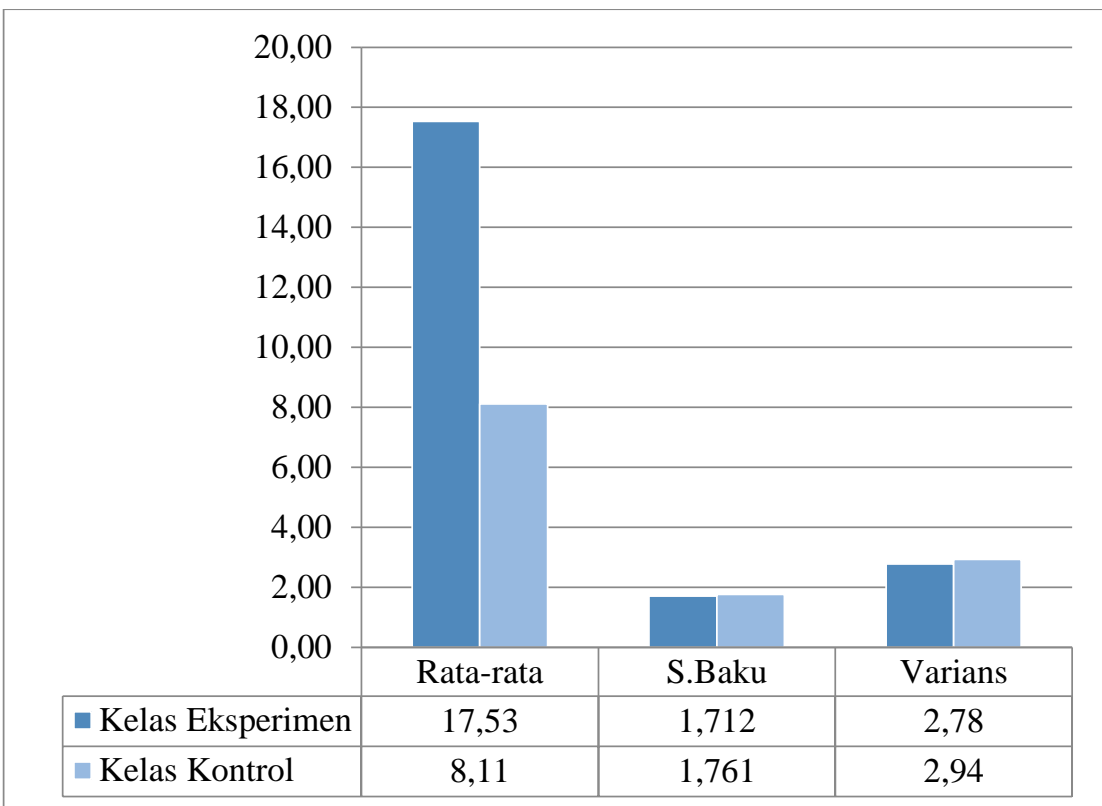

Gambar 2 Diagram Data Post Test Kelas Eksperimen dan Kelas Kontrol

d. Hasil analisis Data

Tabel 5. Data Hasil Uji Normalitas Perkembangan Sosial Anak

\begin{tabular}{|r|r|r|r|r|r|r|}
\multicolumn{1}{|c|}{ Kelas } & \multicolumn{5}{|c|}{ Pre Test } \\
& $\mathrm{L}_{\text {hitung }}$ & $\mathrm{L}_{\text {tabel }}$ & Keterangan & $\mathrm{L}_{\text {hitung }}$ & $\mathrm{L}_{\text {tabel }}$ & Keterangan \\
\hline Eksperimen & 0,160 & 0,195 & Normal & 0,189 & 0,195 & Normal \\
\hline Kontrol & 0,165 & 0,195 & Normal & 0,173 & 0,195 & Normal \\
\hline
\end{tabular}

Tabel 6. Data Hasil Uji Homogenitas Perkembangan Sosial Anak

\begin{tabular}{|c|c|c|c|c|c|}
\hline \multirow[t]{2}{*}{ Data } & $\begin{array}{l}\text { Varians } \\
\text { Terbesar }\end{array}$ & $\begin{array}{l}\text { Varians } \\
\text { Terkecil }\end{array}$ & \multicolumn{2}{|l|}{$F_{\text {hitun }}$} & \multirow[t]{2}{*}{ ] Keterangan } \\
\hline & & & g & tabel & \\
\hline Pre Test & 2.19 & 2.16 & 1,01 &, 27 & Homogen \\
\hline Post Test & 2.94 & 2.78 & 1.06 &, 27 & Homogen \\
\hline
\end{tabular}

Sesuai dengan tujuan penelitian ini yaitu untuk mengetahui adanya pengaruh model pembelajaran make a match terhadap perkembangan sosial anak usia 5-6 tahun di TK Anugrah, maka dilakukan penelitian sebanyak 7 kali pertemuan sebelum dan sesudah perlakuan (pre test dan post test) dilakukan dengan observasi pada anak. Mengumpulkan data penelitian dengan instrumen yang telah disediakan. Setelah diberikan perlakuan pada kelas eksperimen dan kelas kontrol tersebut 
http://jurnaltarbiyah.uinsu.ac.id/index.php/raudhah

e-mail: jurnalraudhah@uinsu.ac.id

p-ISSN: 2338-2163

e-ISSN: 2716-2435

maka diperoleh nilai rata-rata dari kelas eksperimen menggunakan model pembelajaran make a match dan kelas kontrol menggunakan model pembelajaran kelompok. Jadi, terlihat bahwa perkembangan sosial anak pada satu kelas yang berbeda dimana rata-rata perkembangan sosial anak di kelas eksperimen lebih tinggi dari pada rata-rata perkembangan sosial anak di kelas kontrol. Berdasarkan data nilai post test anak ditemukan bahwa terdapat pengaruh yang signifikan antara model pembelajaran make a match terhadap perkembangan sosial anak. Hal ini terlihat dari rata-rata perkembangan sosial anak sebelum dan sesudah diberi perlakuan adalah 7.26 menjadi 17.53. Hal ini juga dibuktikan dari hasil pengujian hipotesis dimana $t_{\text {hitung }}>\mathrm{t}_{\text {tabel }}$ yaitu $24.8969>2,10982 \mathrm{Hal}$ ini sejalan dengan teori behaviorist menurut B.F Skinner menjelaskan bahwa pembelajaran di pengaruhi oleh perilaku yang dibentuk oleh lingkungan eksternalnya. (Khairina, 2016),Maka dari itu pengetahuan merupakan hasil dari interaksi dengan lingkungannya melalui pengkondisian stimulus yang menimbulkan respon. Perubahan lingkungan dapat mempengaruhi pikiran, perasaan dan perilaku anak secara bertahap.

Melalui model pembelajaran make a match pemerolehan skor pada anak memiliki kecenderungan tinggi, hal ini disebabkan oleh beberapa faktor kelebihan model pembelajaran make a match dibandingkan dengan model pembelajaran kelompok pada kelas kontrol. Terdapat tiga hal penting dalam model pembelajaran make a match. Pertama, model pembelajaran make a match merupakan salah satu jenis dari model pembelajaran kooperatif, anak belajar dan bekerja dalam kelompok-kelompok kecil. Model make a match atau mencari pasangan merupakan salah satu alternatif yang dapat diterapkan kepada anak. Penerapan metode ini dimulai dari teknik yaitu anak mencari pasangan kartu yang merupakan jawaban/soal sebelum batas waktunya, anak yang dapat mencocokkan kartunya diberi poin. Salah satu keunggulan tehnik ini adalah anak mencari pasangan sambil belajar mengenai suatu konsep atau topik dalam suasana yang menyenangkan.(Diana, Mutiah, 2015),

Kedua, model pembelajaran Make a Match menuntut anak untuk mencari pasangan kartu soal dan jawaban yang telah dibuat oleh guru dengan batas waktu yang telah ditentukan agar tercipta kerjasama antara anak yang satu dengan anak yang lain. Selain itu, model pembelajaran Make a Match membutuhkan ketelitian, kecermatan, ketepatan, dan kecepatan anak dalam memasangkan/mencocokkan kartu yang dipegang sambil belajar mengenai suatu konsep dalam suasana yang menyenangkan. Metode ini dapat digunakan untuk membangkitkan aktivitas peserta didik belajar dan cocok digunakan dalam bentuk permainan. Ketiga, tujuan yang diperoleh dari pembelajaran model make a match adalah melatih peserta didik agar lebih cermat dan lebih kuat pemahamanya terhadap suatu materi pokok. 
http://jurnaltarbiyah.uinsu.ac.id/index.php/raudhah

e-mail: jurnalraudhah@uinsu.ac.id

p-ISSN: 2338-2163

e-ISSN: 2716-2435

Berdasarkan pendapat tersebut peneliti menyusun kegiatan pembelajaran tidak lepas dari karakteristik tahapan perkembangan anak usia 5-6 tahun. Pemilihan materi kegiatan yang diberikan disesuaikan dengan prinsip penerapan model pembelajaran make a match. Untuk meningkatkan perkembangan sosial anak melalui model pembelajaran make a match, diberikan beberapa kegiatan yang disambut antusias oleh anak. Maka dari pembahasan tersebut dapat diketahui bahwa pembelajaran menggunakan model pembelajaran make a match memiliki pengaruh yang signifikan terhadap perkembangan sosial anak usia 5-6 tahun di TK Anugrah Medan.

\section{SIMPULAN DAN SARAN}

Berdasarkan hasil analisis dan uji statistik serta pembahasan maka disimpukan sebagai berikut:

1. Perkembangan sosial anak usia 5-6 tahun di TK Anugrah telah dibuktikan melalui observasi sebelum menggunakan model pembelajaran make a match pada kelas eksperimen diperoleh dengan nilai rata-rata 7,26 dengan nilai terendah 5, dan nilai tertinggi 9, modusnya 8 , dan mediannya 8. Kemudian menggunakan model kelompok diperoleh dengan nilai rata-rata 8,11 dengan nilai terendah 5 dan nilai tertinggi 12 , modusnya 8 , mediannya 8 , dan simpangan baku 1,761 .

2. Penggunaan model pembelajaran make a match terhadap perkembangan sosial anak usia 5-6 tahun di TK Anugrah, diperoleh dengan nilai rata-rata 17,53 dengan nilai terendah 15 dan nilai tertinggi 20, modusnya 18 dan mediannya 18. Jadi, perkembangan sosial anak usia 5-6 tahun menggunakan model pembelajaran make a match sudah berkembang secara optimal.

3. Berdasarkan penelitian dan hasil analisis data yang telah dilakukan maka dapat disimpilkan bahwa terdapat pengaruh model pembelajaran make a match terhadap perkembangan sosial anak usia 5-6 tahun TK Anugrah. Hal ini dilihat dari hasil analisis data dengan menggunakan uji-t, diketahui nilai post test dari kelas ekperimen nilai $\mathrm{t}_{\text {hitung }}=24.8969$ dengan taraf $\alpha=0,05$ didapat tabel t pada dt 17 diperoleh nilai $\mathrm{t}_{\text {tabel }}=2,10982$. Karena $\mathrm{t}_{\text {hitung }}>\mathrm{t}_{\text {tabel }}$ maka $\mathrm{H}_{0}$ : ditolak, $\mathrm{H}_{\mathrm{a}}$ : diterima. Hasil perhitungan tersebut menunjukkan bahwa $\mathrm{t}_{\text {hitung }}>\mathrm{t}_{\text {tabel }}$, sehingga penelitian signifikan.

Berdasarkan hasil penelitian dan kesimpulan di atas, maka sebagaitindak lanjut dari penelitian ini disarankan beberapa hal sebagai berikut:

1. Kepala sekolah hendaknya menjadi fasilitator maupun motivator untuk pendidik dan peserta didik berupa pengadaan sarana dan prasarana, yang mendukung terciptanya prestasi atau tujuan belajaryang diharapkan. 
http://jurnaltarbiyah.uinsu.ac.id/index.php/raudhah e-mail: jurnalraudhah@uinsu.ac.id

p-ISSN: 2338-2163

2. Para pendidik perlu diperkenalkan model pembelajaran make a match yang menghubungkan muatan akademik dengan konteks kehidupan anak mengingat, terdapat kecenderungan pada pemikiran bahwa anak akan belajar lebih baik jika lingkungan diciptakan alamiah sehingga belajar lebih bermakna jika anak mengalami apayang dipelajarinya, bukan mengetahui.

3. Bagi orangtua disarankan untuk melatih anak kembali di rumah dalam menerapkan langkahlangkah pembelajaran make a match setelah diajarkan di sekolah dengan cara mentimulus anak untuk mengamati lingkungan disekitar rumah.

\section{DAFTAR PUSTAKA}

Anita Yus, 2016. Model Pendidikan Anak Usia Dini, Jakarta: Kencana Prenada Media Group Anugrah, Ali. 2009. Metode Pengembangan Sosial Emosional, Jakarta: Universitas terbuka

B. Uno, Hamzah. 2012. Model Pembelajaran Menciptakan Proses Belajar Mengajar yang Kreatif dan Efektif, Jakarta: Bumi Aksara

Djoehaeni, Henny Masitoh, Ocih Setiasih. 2015. Pendekatan Belajar Aktif di Taman Kanakkanak.Jakarta: Departemen Pendidikan Nasional Direktorat Jenderal Pendidikan Tinggi

Dimyati, Johni. 2016. Pembelajaran Terpadu Untuk Taman Kanak-Kanak/Raudhatul Athfal dan Sekolah Dasar, Jakarta: Kencana

Fadillah, Muhammad. 2015. Desain Pembelajaran PAUD, Depok: Ar Ruzz Media

Fatmawati, Nia., Pinka Olivia, Ari Sofia. 2019, Efektifitas Penggunaan Model Pembelajaran Make a Match Terhadap Perkembangan Interaksi Sosial Anak, FKIP Universitas Lampung

Hartina, Sitti. 2018. Perkembangan Peserta Didik, Bandung: PT Refika Aditama

Hasnida. 2015. Analisa Kebutuhan Anak Usia Dini, Jakarta: Luxima Media

Husrizal, Dedy \& Nasriah. 2014. Konsep Dasar PAUD, Medan: Unimed Press

Jayanti, Dewi Ayu Surya, Aditya Antara, Rahayu Ujianti. 2019, Fakultas Ilmu Pendidikan Universitas Pendidikan GaneshaSingaraja, Pengaruh Model Pembelajaran Kooperatif Tipe Make a Match Terhadap Kepercayaan Diri Kelompok B Gugus I

Junaidi. 2017. Metode Pendidikan Rasulullah Inspirasi Bagi Guru Sejati, Medan: Perdana Publishing

Khadijah. 2016. Pendidikan Prasekolah, Medan: Perdana Publishing

Khadijah. 2016. Pengembangan Kognitif Anak Usia Dini, Medan: Perdana Publishing

Khairina.2016. Perkembangan Anak Usia RA, Medan: Diktat

Maisarah. 2019. Metodologi Penelitian Pendidikan Pendekatan Kuantitatif, Medan: Akasha Sakti

Mansur. 2015. Pendidikan Anak Usia Dini dalam Islam, Yogyakarta: Pustaka Pelajar 
http://jurnaltarbiyah.uinsu.ac.id/index.php/raudhah e-mail: jurnalraudhah@uinsu.ac.id

p-ISSN: 2338-2163

e-ISSN: 2716-2435

Mutiah, Diana. 2015. Psikologi Bermain Anak Usia Dini, Jakarta: Kencana Prenada Media Group

Mustofa, Bisri. 2016. Dasar-dasar Pendidikan Anak Pra Sekolah, Yogyakarta: Parama Ilmu

Ndari, Susanti Selaras,. dkk. 2018. Metode Perkembangan Sosial Emosi Anak Usia Dini, Jawa Barat:

Edu Publisher

Nuoorlaila, Iva. 2015.Panduan Lengkap Mengajar PAUD, Yogyakarta: Pinus Book Publishe

Nurmalitasari, Femmi. 2015.Perkembangan Sosial Emosi Pada Anak Usia Prasekolah, Fakultas Psikologi UGM(Vol 23) No. 2

Rahyuni, 2014, Penerapan Model Pembelajaran Make A Match Berbantuan Media Kartu Bergambar untuk Meningkatkan Perkembangan Sosial Anak.Jurnal PG PAUD UNDIKSHA 2(01)

Sugandhi, Nani M \& Syamsu Yusuf. 2014. Perkembangan Peserta didik, Depok: PT Raja Grafindo Sujiono, Yuliani Nurani. 2014. Konsep Dasar Pendidikan Anak Usia Dini, Jakarta: Indeks

Suryana, Dadan. 2016. Pendidikan Anak Usia Dini Stimulasi dan Aspek Perkembangan Anak, Jakarta: Kencana

Susanto, Ahmad. 2015.Bimbingan dan Konseling di Taman Kanak-Kanak, Jakarta: Prenada Media Group

Ulfah, Maulidya \&Suyadi. 2015.Konsep Dasar PAUD, Bandung: PT Remaja Rosdikarya

Waridah, Oksiana Weni, Yakobus Ason, 2016, Penerapan Model Pembelajaran Kooperatif Tipe Make a Match Terhadap Aspek Perkembangan Kognitif Dan Sosial Emosional Pada Anak Usia Dini TK Negeri Pembina, STKIP Melawi

Wibowo, Agus. 2017. Pendidikan Karakter Anak Usia Dini, Yogyakarta: Pustaka Pelajar

Wiyani, Ardy. 2016. Konsep Dasar PAUD, Yogyakarta: Gava Media

Umayah, 2017. Perkembangan Sosial Pada Anak Usia Dini, As-sibyan Vol 2 No. 1 